Article

\title{
Short-Term Rapamycin Preconditioning Diminishes Therapeutic Efficacy of Human Adipose-Derived Stem Cells in a Murine Model of Multiple Sclerosis
}

\author{
Rachel M. Wise ${ }^{1,2}$, Mark A. A. Harrison ${ }^{1,2}$, Brianne N. Sullivan ${ }^{1,2}$, Sara Al-Ghadban ${ }^{2,3}$ (D), \\ Sarah J. Aleman ${ }^{1}$, Amber T. Vinluan ${ }^{1}$, Emily R. Monaco ${ }^{1}$, Umberto M. Donato ${ }^{1}$, \\ India A. Pursell ${ }^{2}$ and Bruce A. Bunnell $2,3,4, *$ D \\ 1 Neuroscience Program, Tulane Brain Institute, Tulane University School of Science \& Engineering, \\ New Orleans, LA 70118, USA; rwise@tulane.edu (R.M.W.); mharri26@tulane.edu (M.A.A.H.); \\ bsulliv7@tulane.edu (B.N.S.); saleman@tulane.edu (S.J.A.); avinluan@tulane.edu (A.T.V.); \\ emonaco@tulane.edu (E.R.M.); udonato1@tulane.edu (U.M.D.) \\ 2 Center for Stem Cell Research \& Regenerative Medicine, Tulane University School of Medicine, \\ New Orleans, LA 70112, USA; sara.al-ghadban@unthsc.edu (S.A.-G.); ipursell@tulane.edu (I.A.P.) \\ 3 Department of Microbiology, Immunology and Genetics, University of North Texas Health Science Center, \\ Fort Worth, TX 76107, USA \\ 4 Department of Pharmacology, Tulane University School of Medicine, New Orleans, LA 70112, USA \\ * Correspondence: bruce.bunnell@unthsc.edu
}

Received: 24 August 2020; Accepted: 28 September 2020; Published: 30 September 2020

\begin{abstract}
Human adipose-derived stem cells (ASCs) show immense promise for treating inflammatory diseases, attributed primarily to their potent paracrine signaling. Previous investigations demonstrated that short-term Rapamycin preconditioning of bone marrow-derived stem cells (BMSCs) elevated secretion of prostaglandin E2, a pleiotropic molecule with therapeutic effects in the experimental autoimmune encephalomyelitis (EAE) model of multiple sclerosis (MS), and enhanced immunosuppressive capacity in vitro. However, this has yet to be examined in ASCs. The present study examined the therapeutic potential of short-term Rapamycin-preconditioned ASCs in the EAE model. Animals were treated at peak disease with control ASCs (EAE-ASCs), Rapa-preconditioned ASCs (EAE-Rapa-ASCs), or vehicle control (EAE). Results show that EAE-ASCs improved clinical disease scores and elevated intact myelin compared to both EAE and EAE-Rapa-ASC animals. These results correlated with augmented $C D 4^{+} T$ helper $\left(T_{h}\right)$ and $T$ regulatory $\left(T_{\text {reg }}\right)$ cell populations in the spinal cord, and increased gene expression of interleukin-10 (IL-10), an anti-inflammatory cytokine. Conversely, EAE-Rapa-ASC mice showed no improvement in clinical disease scores, reduced myelin levels, and significantly less $T_{h}$ and $T_{\text {reg }}$ cells in the spinal cord. These findings suggest that short-term Rapamycin preconditioning reduces the therapeutic efficacy of ASCs when applied to late-stage EAE.
\end{abstract}

Keywords: adipose tissue-derived stem cells (ASCs); multiple sclerosis (MS); experimental autoimmune encephalomyelitis (EAE); Rapamycin; immunomodulation; inflammation; demyelination

\section{Introduction}

Multiple sclerosis (MS) is an inflammation-driven autoimmune disease caused by aberrant activation and infiltration of peripheral immune cells into the central nervous system (CNS), and subsequent destruction of myelin-producing oligodendrocytes [1]. MS affects an estimated 2.3 million people worldwide, with over $85 \%$ of patients presenting with the relapsing-remitting form of the disease [2,3]. Many of these patients develop secondary progressive MS-at which point, disease 
progressively worsens without periods of remission, and most available therapies lose their efficacy [4]. The current treatments for MS are primarily disease-modifying and immunosuppressive drugs that target the inflammation, but not the demyelination and neurodegenerative damage that cause the primary symptoms of MS [5]. It is, therefore, imperative to explore safe and effective regenerative therapies to address these significant limitations. The experimental autoimmune encephalomyelitis (EAE) animal model is the best characterized for the study of pathogenic mechanisms in MS. In the EAE mouse, the induction of myelin-specific autoreactive T cells results in a cascade of CNS inflammation, demyelinating lesion formation, and ascending motor function deterioration that peaks 2 to 3 weeks post-immunization [6].

Adipose tissue-derived stem cells (ASCs) are characterized by their multipotency and self-renewal capacity. However, it is their potent immunoregulatory properties that make them a promising therapeutic intervention for autoimmune, inflammatory, and neurodegenerative diseases [7]. ASCs have significant benefits over other tissue sources of mesenchymal stem cells (MSCs), such as bone marrow, due to their ease of harvest, higher stem cell yield, enhanced secretion of immune-modifying factors, and reduced immunogenicity post-transplant $[8,9]$. Our lab has repeatedly demonstrated the beneficial effects of ASC treatment in the EAE model of MS. We have shown that ASCs suppress proliferation of type $1 \mathrm{~T}$ helper $\left(\mathrm{Th}_{1}\right)$ cells, promote $\mathrm{T}$ regulatory $\left(\mathrm{T}_{\text {reg }}\right)$ cells and alternatively-activated macrophages (M2), dampen pro-inflammatory cytokine production, reduce CNS infiltration and demyelinating lesions, and improve overall disease outcomes [10-13]. The mechanisms driving the ability of ASCs to slow or reverse disease progression in EAE are not fully defined, but there is substantial evidence that the primary benefit of ASC therapy is their paracrine modulation of immune cell populations rather than their engraftment into CNS tissues and direct replacement of oligodendrocytes. Melief et al. demonstrated the superior secretory activity of ASCs compared to BMSCs, which is associated with better suppression of PBMC proliferation and differentiation into mature dendritic cells [14]. This secretory activity is also correlated with the therapeutic activity of ASCs in the EAE model, as inhibition of secreted immunomodulatory factors including PGE2 mitigates immunoregulatory capacity [15].

One study by Payne and collaborators demonstrated the superior homing ability of human ASCs to the inflamed CNS in the EAE mouse model, which was correlated with improved disease scores, reduced CNS infiltration and demyelination in ASC-treated animals [16]. However, an investigation by Constantin et al. showed that while a small subset of IV-injected GFP-labeled ASCs were observed in spinal cord tissues up to 6 weeks post-treatment, less than $2 \%$ co-expressed mature glial markers, making it unlikely that engraftment and transdifferentiation of ASCs contributes significantly to their therapeutic effects [17]. Another report showed persistence of injected cells in the CNS of EAE mice up to 25 days post-injection but did not assess engraftment or differentiation [18]. Additionally, this study based these assumptions on human transcript levels in the EAE rat brain, not on the visualization of cells. Thus, most evidence of ASC therapy in EAE suggests that their primary benefit derives from their homing to sites of inflammation, modifying innate and adaptive immune cells through paracrine activity, and changing the populations that then infiltrate the CNS and determine the course of disease.

Despite substantial preclinical success, translation to human trials faces numerous obstacles due to limited and variable ASC immunosuppression in the post-transplant pathological environment. Furthermore, donor characteristics such as advanced age or obesity status negate the therapeutic effect of ASCs, and strategies to restore their efficacy would reduce donor-to-donor variability and drastically widen the potential donor pool $[13,19,20]$.

To address these challenges, in vitro preconditioning strategies have been developed to improve both the survival and immune response of MSCs to stressful stimuli [21]. One of the most successful strategies is the immunosuppressive drug Rapamycin (Rapa), which is FDA approved for treatment of several cancers, both alone and in combination with chemotherapeutic agents [22]. The preconditioning of MSCs with Rapa results in substantial improvement of their immunoregulatory function in animal models of graft vs. host disease and cutaneous wound healing [23,24]. Moreover, Rapa exposure 
has demonstrated an effective reversal of MSC senescence [25-27], resiliency to apoptosis-inducing stimuli [28], and robust enrichment of immunomodulatory function [29-31]. Furthermore, short-term Rapa exposure caused an increase in both cyclooxygenase-2 (COX2) and prostaglandin-E2 (PGE2) in bone marrow-derived mesenchymal stem cells (BMSCs) in vitro [30]. PGE2, the synthetic byproduct of COX2 enzymatic activity on arachidonic acid, is typically upregulated in response to inflammatory conditions and modulates innate and adaptive immune cells [32,33]. This upregulation correlated with enhanced suppression of proliferation of peripheral blood mononuclear cells (PBMCs) and splenocytes [30]. However, it has yet to be determined whether the beneficial effects of Rapa seen in vitro can be extrapolated to ASC therapy for EAE.

Recent in vivo evidence from a study of BMSC administration in EAE mice suggests that one BMSC-derived signaling molecule, PGE2, may constitute a substantial part of the therapeutic efficacy of MSC therapy in EAE [34]. Matysiak et al. found that PGE2 inhibition following BMSC treatment significantly reduced the therapeutic effect [34]. Intriguingly, PGE2 has exhibited both beneficial and harmful roles in EAE progression. In early preclinical phases, PGE2 receptor expression and secretion are enhanced in monocytes and macrophages. This is associated with elevated inflammatory $\mathrm{T}$ cell activation and pro-inflammatory cytokine production [35]. In the later prodromal phase of EAE, expression of PGE2 receptors is increased on T cells, which demonstrate enhanced migration, expression of matrix metallopeptidase 9 (MMP9), and invasion of the lumbar spinal cord [35]. Additionally, PGE2 and its receptors are elevated in active lesions in EAE and MS [36], and knockout studies show that PGE2 activity is crucial for the development of EAE $[35,37]$. However, it has been demonstrated that PGE2 can also suppress disease progression by protecting or restoring the integrity of the blood-brain barrier (BBB) if administered during a critical window [37]. Importantly, the immunological consequences of PGE2 overexpression during active EAE remain unexplored.

Faced with conflicting evidence on the contribution of PGE2 to EAE pathophysiology, and the reported elevation of PGE2 following short-term Rapa in ASCs, the present study investigates the consequences of this preconditioning strategy in the EAE model of CNS inflammation. Following disease induction, treatments with either ASCs (EAE-ASC), Rapa-preconditioned ASCs (EAE-Rapa-ASC), or vehicle control (EAE) were compared for their ability to improve symptoms and performance on the rotarod task, mitigate CNS cellular infiltration and damaged myelin, and modify $\mathrm{T}$ cell populations in the lymphoid organs and the spinal cord. The data demonstrate that while ASCs can improve most of the examined disease outcomes when applied at days post-induction (DPI) 20, Rapa-ASCs proved to be no more effective than vehicle treatment. These findings, though unexpected, highlight the necessity of in vivo assessment of novel treatment strategies. These findings suggest that further investigation of Rapa-ASCs earlier in EAE may yield greater insight into the dynamic role of PGE2 in disease pathogenesis.

\section{Materials and Methods}

\subsection{Induction of EAE with Myelin Oligodendrocyte Glycoprotein (MOG) ${ }_{35-55}$ Peptide}

Reagents for EAE induction were prepared by diluting $\mathrm{MOG}_{35-55}$ peptide $(2 \mathrm{mg} / \mathrm{mL}$; Cat \#: AS-60130-5; AnaSpec, Fremont, CA, USA) in UltraPure ${ }^{\mathrm{TM}}$ DNase/RNase-Free distilled water (ThermoFisher, Waltham, MA, USA) and emulsifying with equal parts of Complete Freund's Adjuvant (BD Biosciences, Franklin Lakes, NJ, USA) containing $8 \mathrm{mg} / \mathrm{mL}$ Mycobacterium tuberculosis H37RA (Cat \#: 231131; BD Biosciences, San Jose, CA, USA) by passage through glass Luer-Lok syringes and a micro-emulsifying needle for $45 \mathrm{~min}$. The emulsion was then transferred to $1 \mathrm{~mL}$ Luer-Lok syringes with $27 \mathrm{G} \frac{1}{2}$ " needles. Pertussis toxin was diluted in UltraPure ${ }^{\mathrm{TM}}$ water $(2 \mathrm{ng} / \mu \mathrm{L}$; Cat \#: 181; List Biologicals Laboratories, Campbell, CA, USA) and transferred to syringes as described above. Female 6-8-week-old C57Bl/6 mice (Charles River Laboratories, Wilmington, MA, USA) were anesthetized using $5 \%$ isoflurane gas then given bilateral subcutaneous flank injections of $100 \mu \mathrm{L}$ MOG emulsion near the base of the tail ( $200 \mu \mathrm{L}$ total per mouse). Concurrently, mice were given a single 
intraperitoneal (IP) injection of $100 \mu \mathrm{L}$ pertussis toxin. Mice received a second IP injection of $100 \mu \mathrm{L}$ pertussis toxin $48 \mathrm{~h}$ later to complete the EAE induction process. Sham-induced control mice received equivalent injections of Hank's balanced salt solution (HBSS; ThermoFisher, Waltham, MA, USA). All animal procedures were authorized by the Institutional Animal Care and Use Committee at Tulane University and followed state and federal National Institute of Health's animal welfare guidelines. Mice were given food pellets and water ad libitum. Using a standard clinical rating scale, mice were scored daily for disease progression by blinded researchers starting at 1 day post-induction (DPI) and going through DPI 30. Briefly, mice were given a score from 0 to 5: 0 no detectable signs of disease; 1 , tail atony with abnormal gait; 2 , hind limb weakness; 3 , partial hind limb paralysis; 4 , complete hind limb paralysis; 5 , moribund or dead.

\subsection{Rotarod Analysis}

To assess balance and coordination in vehicle-treated (EAE, $n=5)$, ASC-treated (EAE-ASC, $n=5$ ) and Rapa-preconditioned ASC-treated (EAE- Rapa-ASC, $n=6$ ) mice, the Roatmex-5 rotarod system (Columbus Instruments, Columbus, OH, USA) for small rodents was used as previously described by others [38,39]. Each experimental mouse was subjected to three training sessions from DPI 3 to 5. Following that, the mice were tested weekly at a fixed rotational speed of $4 \mathrm{rpm}$ for a maximum time of $2 \mathrm{~min}$. The latency to fall across three consecutive trials was recorded and group mean \pm SEM was reported.

\subsection{Cells and Cell Culture}

Primary human ASCs were purchased from LaCell LLC (New Orleans, LA, USA). Individual ASC cell lines were fully characterized individually prior to being pooled [19,20,40-42]. ASCs from 5 healthy donors were pooled and expanded in complete culture medium (CCM) consisting of Minimum Essential Medium alpha (Cat \#: 12561; Gibco, Grand Island, NY, USA) supplemented with 10\% heat-inactivated Hyclone characterized fetal bovine serum (FBS, Cat \#: SH30396.03; ThermoFisher, Waltham, MA, USA), and 1\% Penicillin-Streptomycin (Cat \#: 15140122; 10,000 U/mL, ThermoFisher, Waltham, MA, USA) in a humidified, $5 \% \mathrm{CO} 2$ incubator. Media was changed every $2-3$ days until cells achieved $70-80 \%$ confluence. ASCs were used at passage 5 for the experiments.

\subsection{Preparation and Injection of Cells}

Based on our previous EAE studies, DPI 20 was chosen for late-stage treatment [11]. On DPI 20, cultured ASCs were washed with 1XPBS (ThermoFisher, Waltham, MA, USA) then treated for $4 \mathrm{~h}$ with either control CCM (ASCs) or Rapamycin-supplemented CCM (Rapa-ASCs; 500 nM; Cat \#: 553211; Millipore Sigma, Burlington, MA, USA). Cells were then washed with 1XPBS, harvested with $0.25 \%$ trypsin/1 mM EDTA (Cat \#: 25200056; ThermoFisher, Waltham, MA, USA), and live cells were counted using a trypan blue exclusion assay. Finally, $1 \times 10^{6}$ ASCs or Rapa-ASCs were resuspended in $100 \mu \mathrm{L}$ HBSS and transferred to $1 \mathrm{~mL}$ Luer-Lok syringes with 27G, $\frac{1}{2}$ " needles for IP injections as previously described $[11,19,20]$. Mice with a clinical score of 2 or greater on DPI 20 were randomly assigned to treatment groups and received $100 \mu \mathrm{L}$ IP injections of $1 \times 10^{6}$ : ASCs (EAE-ASC, $n=5$ ), Rapa-ASCs (EAE-Rapa-ASC, $n=6$ ), or HBSS (EAE, $n=5$ ) for vehicle control.

\subsection{Tissue Harvest and Processing}

EAE mice were euthanized by $\mathrm{CO}_{2}$ asphyxiation and the spleens and spinal cords of each mouse were harvested. Lumbar sections of spinal cords (L3-L6) were removed and stored at room temperature (RT) in neutral buffered formalin for subsequent paraffin embedding. Remaining spinal cord tissue was homogenized in Qiazol lysis reagent (Cat \#: 79306; Qiagen, Germantown, MD, USA) and immediately stored at $-80{ }^{\circ} \mathrm{C}$ for future experiments. EAE spleens were mechanically dissociated by passing through a $100 \mu \mathrm{m}$ cell strainer using the blunt ends of syringes into a $50 \mathrm{~mL}$ conical tube and centrifuged at $2000 \mathrm{rpm}$ for $5 \mathrm{~min}$ to pellet. The cells were then incubated with red blood cell lysis (company info) 
for $5 \mathrm{~min}$ at RT. Splenocytes were then washed with PBS, counted using trypan blue exclusion assay, and processed for flow cytometric analysis or stored in Qiazol lysis reagent at $-80^{\circ} \mathrm{C}$ for subsequent RNA isolation.

\subsection{Flow Cytometric Staining and Analysis}

Splenocytes were counted and resuspended in 1XPBS containing the cell viability indicator GhostDye 780 (Cat \#: 13-0865; Tonbo Biosciences, San Diego, CA, USA) and incubated for $30 \mathrm{~min}$ at $4{ }^{\circ} \mathrm{C}$. Cells were then washed twice with flow staining buffer containing $1 \%$ bovine serum albumin (BSA; Sigma-Aldrich, St. Louis, MO, USA), spun down and resuspended in flow staining buffer to a final concentration of $1 \times 10^{6}$ cells $/ \mathrm{mL}$. Next, cells were stained with fluorescently conjugated anti-mouse antibodies against CD3 (Cat \#: 11-0032-82, ThermoFisher, Waltham, MA, USA), CD4 (Cat \#: 56004282, Fisher Scientific, Lenexa, KS, USA), and CD8 (Cat \#: 12008183, eBioscience, San Diego, CA, USA). Samples requiring intracellular staining were incubated in a fixation/permeabilization solution (Cat \#: 88-8824-00; ThermoFisher, Waltham, MA, USA) and stained with a fluorescently conjugated anti-mouse antibody against intracellular FOXP3 (Cat \#: 12400-31; SouthernBiotech, Birmingham, AL, USA). All other samples were washed and fixed using $1 \%$ paraformaldehyde. Samples were stored at $4{ }^{\circ} \mathrm{C}$ until flow cytometric analysis could be performed using a Gallios Flow Cytometer (Beckman Coulter). A minimum of $1 \times 10^{4}$ events per sample were captured and analyzed with Kaluza Analysis 2.1 software (Beckman Coulter).

\subsection{RNA Isolation and Quantitative Reverse-Transcription PCR (qRT-PCR)}

Homogenized EAE spleens and spinal cords stored in Qiazol at $-80^{\circ} \mathrm{C}$ were thawed and RNA was extracted from each sample using the Qiagen RNeasy Plus mini kit (Cat \#: 74136, Qiagen, Germantown, $\mathrm{MD}$, USA). A total of $1 \mu \mathrm{g}$ of mRNA per sample was synthesized into cDNA using the Applied Bioscience High-Capacity cDNA Reverse Transcription kit (Cat \#: 4368814, ThermoFisher, Waltham, MA, USA). qRT-PCR was performed with SsoAdvanced Universal SYBR Green Supermix (Cat \#: 1725271, Bio-Rad, Hercules, CA, USA). Mouse-specific, exon-spanning primers were designed using the Primer-BLAST online tool4 and synthesized by Integrated DNA Technologies (Coralville, IA, USA). Forward and reverse primer sequences used for qRT-PCR are listed in Table 1. All reactions were performed in duplicate. Analysis was completed using the $2^{-\Delta \Delta C t}$ method to calculate the relative fold-change in transcript expression after normalization to the reference gene, $\beta$-actin. Data for all groups were normalized to the vehicle control group (EAE) for relative quantification of mRNA expression levels.

Table 1. Primer Sequences.

\begin{tabular}{lll}
\hline \multicolumn{1}{c}{ Gene } & Forward $\left(\mathbf{5}^{\prime}-\mathbf{3}^{\prime} \mathbf{)}\right.$ & Reverse $\left(\mathbf{5}^{\prime}-\mathbf{3}^{\prime} \mathbf{)}\right.$ \\
\hline Beta-actin & GTGGGCCGCCCTAGGCACCA & TTAGCACGCACTGTAGTTTCTC \\
\hline TGF- $\beta$ & CGTCAGACATTCGGGAAGCA & TGCCGTACAACTCCAGTGAC \\
\hline$I L-10$ & GCTCTTGCACTACCAAAGCC & CTGCTGATCCTCATGCCAGT \\
\hline$I L-4$ & GGTCTCAACCCCCAGCTAGT & GCCGATGATCTCTCTCAAGTGAT \\
\hline Tbet & CACTAAGCAAGGACGGCGAA & TAATGGCTTGTGGGCTCCAG \\
\hline GATA3 & TGTCTGCGAACACTGAGCTG & CGATCACCTGAGTAGCAAGGA \\
\hline FOXP3 & CCCATCCCCAGGAGTCTTG & ACCATGACTAGGGGCACTGTA \\
\hline
\end{tabular}

\subsection{Histological Analysis of Spinal Cords}

Formalin-fixed lumbar spinal cords were paraffin embedded, cut into $5 \mu \mathrm{m}$ thick sections, and mounted on microscope slides. Sections were stained with hematoxylin (Cat \#: 7231; ThermoFisher, Waltham, MA, USA) and eosin (Cat \#: 7111; ThermoFisher, Waltham, MA, USA) to assess cellular 
infiltration, or Luxol fast blue (LFB; cat\# IW-3005, IHC World, Ellicott City, MD, USA) to determine myelin content. Slides were imaged using a Zeiss Axio Scan.Z1 slide scanner (Carl Zeiss Microscopy; Gottingen, Germany), and brightfield images were analyzed using the ZEN3.1 image analysis software (Carl Zeiss Microscopy). Four animals were randomly selected from each group, and at least 6 spinal cord sections across a $400 \mu \mathrm{m}$ region were analyzed by a blinded researcher. Myelin content and cellular infiltration were calculated as the number of positive pixels/total number of pixels and reported as \% total area.

\subsection{Statistical Analysis}

All data are presented as the mean \pm SEM. GraphPad PRISM 8 (GraphPad; San Diego, CA, USA) was used to perform all statistical analyses. Results of single time points were compared using one-way analysis of variance (ANOVA), and results across several time points were compared using a mixed effects model of repeated measures ANOVA followed by a Tukey's post-hoc test. Asterisks $\left(^{*}\right)$ denote statistical significance between the HBSS vehicle-treated control group and the ASC-treated or Rapa-ASC-treated groups: ${ }^{*} p<0.05 ;{ }^{* *} p<0.01$; and ${ }^{* * *} p<0.001$. Pound signs (\#) denote statistical significance between the ASC-treated and Rapa-ASC-treated groups: \# $p<0.05$; \#\# $p<0.01$; and \#\#\# $p<0.001$.

\section{Results}

\subsection{ASCs, but Not Rapa-ASCs, Modestly Improved Rotarod Performance in EAE Mice}

Human ASCs have shown considerable therapeutic ability in the EAE mouse model of MS [10,15,18-20,43,44]. Thus, we investigated whether a novel Rapa preconditioning approach enhanced or inhibited their immunomodulatory capacity. After the induction of EAE, mice were scored daily for disease progression using a common clinical rating scale. At DPI 20, a time point representing the height of disease severity, animals were randomly assigned to receive either control ASCs (EAE-ASC, $n=5$ ), 4-h Rapa-preconditioned ASCs (EAE-Rapa-ASC, $n=6$ ) or vehicle control treatment (EAE, $n=5)$ (Figure 1A). We demonstrate that the ASC-treated group showed a marked improvement in disease scores compared to both vehicle control and Rapa-ASC groups by DPI 30, indicating the successful reduction in disease severity (Figure 1B).

Motor coordination and balance were analyzed weekly by fixed speed rotarod testing, to assess functional recovery. One week before treatment (DPI 14) and before assignment to groups randomly, all EAE animals showed deficits in rotarod performance compared to sham-induced animals (Figure 1C). Twenty-four hours after ASC treatment, on DPI 21, the EAE-ASC group resulted in the most significant improvement on the rotarod task demonstrated by the increased latency to fall. All animals began to show signs of improvement by DPI 28.

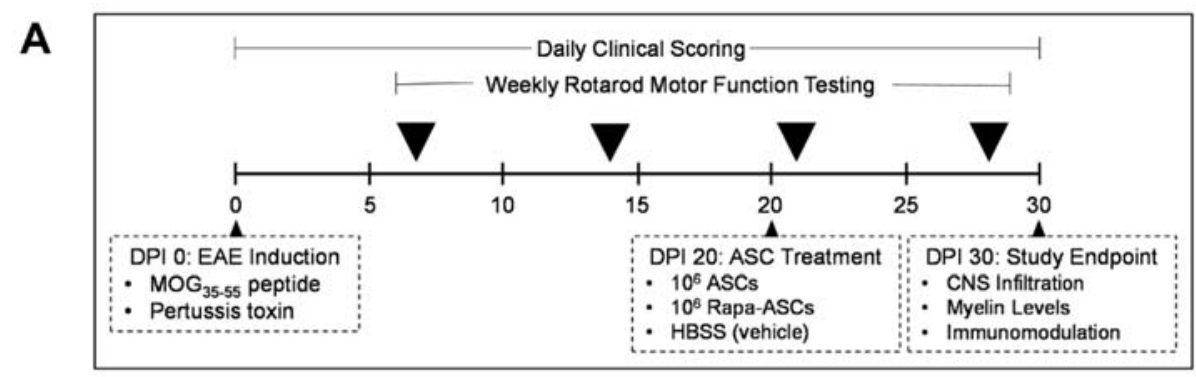

Figure 1. Cont. 


\section{B}

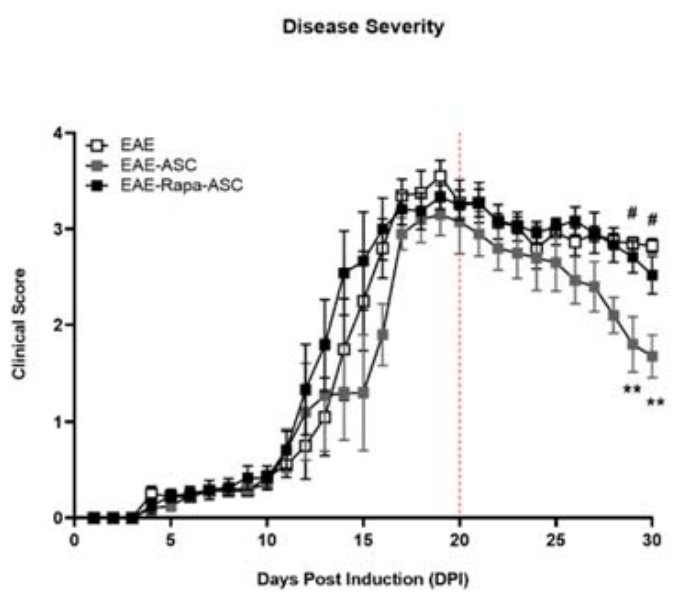

\section{C}

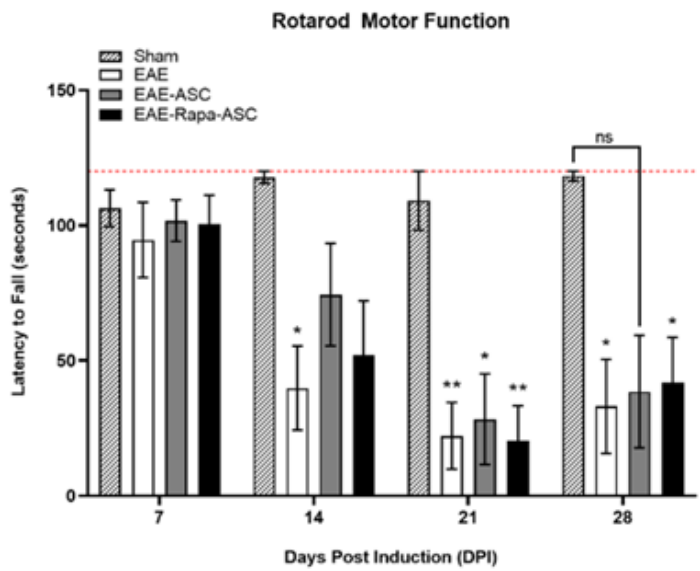

Figure 1. Rapa-ASCs do not reduce disease severity when administered at late-stage EAE. (A) Experimental design illustrating the timeline of EAE induction and schedule of clinical and behavioral assessments. (B) Severity of disease progression for each group over the course of 30 days, as determined by traditional clinical scoring system. (C) Balance and motor coordination evaluation with a fixed speed rotarod performance test. Reported as latency to fall. All data are presented as the mean \pm SEM. Statistical analysis was performed using a mixed effects model of repeated measures analysis of variance (ANOVA) and Tukey's post-hoc multiple comparisons test. Statistical differences between EAE and EAE-ASC are marked with ${ }^{*} p<0.05 ;{ }^{* *} p<0.01$. Statistical differences between EAE-ASC and EAE-Rapa-ASC are marked with \# $p<0.05$. Abbreviations: EAE, experimental autoimmune encephalomyelitis; Rapa, Rapamycin; MOG, myelin oligodendrocyte glycoprotein.

\subsection{Reduced Myelin Content of the CNS in ASC-, but Not Rapa-ASC-Treated EAE Mice}

One of the most critical pathological hallmarks of MS and EAE is the extravasation of peripheral immune cells into the CNS and subsequent destruction of myelin in the spinal cord. In this study, histological analysis of EAE lumbar spinal cord sections was used to assess cellular infiltration and demyelination. As demonstrated by hematoxylin staining of cell nuclei, there was no quantifiable difference in spinal cord cellularity in EAE mice receiving ASC treatments compared with vehicle-treated EAE mice (Figure 2A,B). Conversely, intact myelin levels, measured by dark blue LFB staining, were significantly enhanced in EAE-ASC mice compared to EAE controls (Figure 2C,D). Thus, ASC treatment at DPI 20 is capable of either preventing further myelin damage or repairing the extant damage. Furthermore, Rapa-ASC treatment resulted in substantially reduced myelin levels compared to both vehicle and EAE-ASC mice, suggesting that Rapa-preconditioned ASCs may exacerbate rather than mitigate the demyelination seen in the EAE spinal cord. 
A

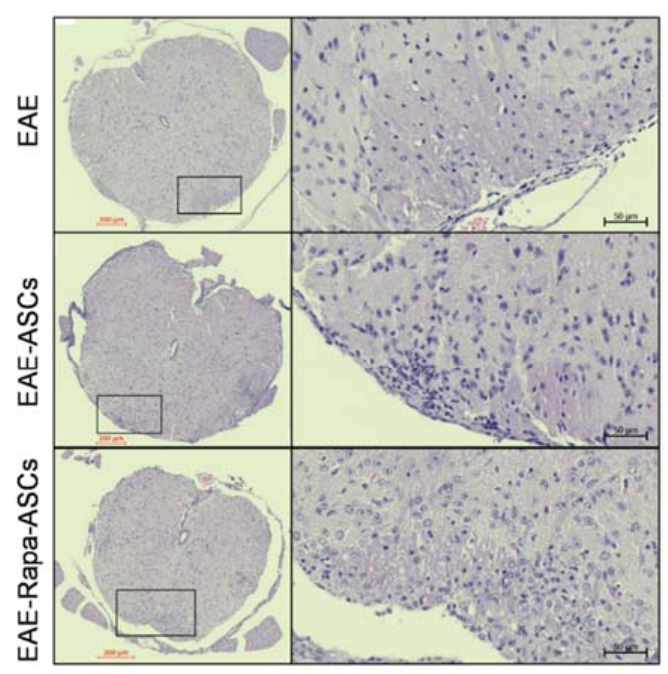

C

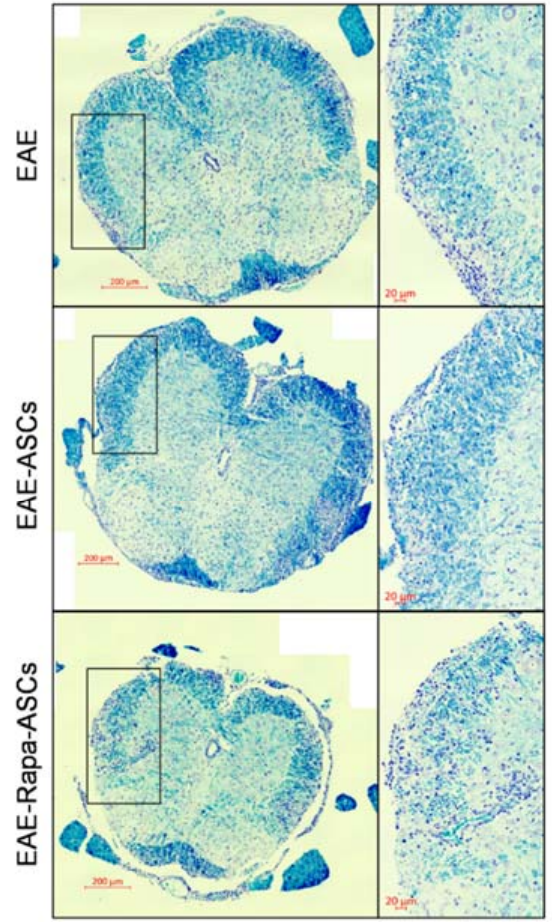

B

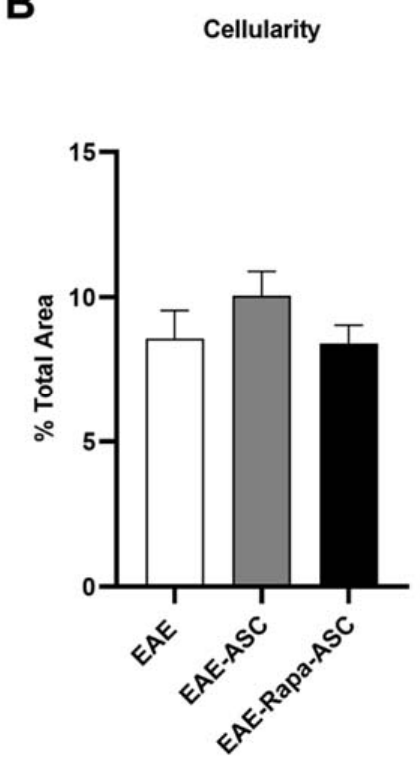

D

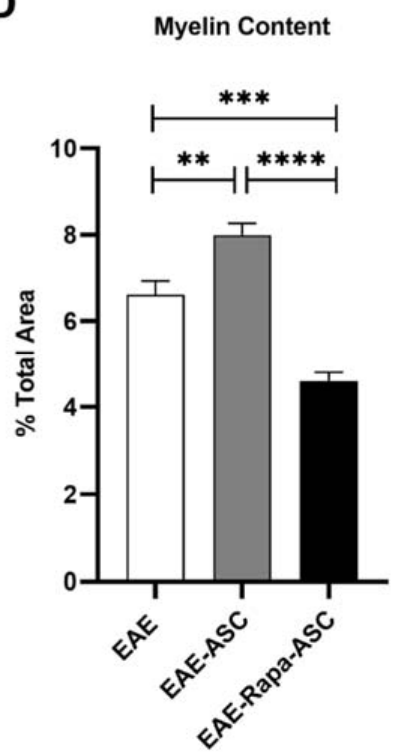

Figure 2. Rapa-ASCs result in reduced intact myelin when administered during late-stage EAE. Representative images of (A) hematoxylin and eosin-stained and (C) Luxol fast blue-stained lumbar spinal cord sections from vehicle-treated EAE (EAE), ASC-treated EAE (EAE-ASC) and Rapa-ASC-treated EAE (EAE-Rapa-ASC) mice. Quantitative comparison of (B) cellular infiltration and (D) myelin content in spinal cord sections between each group $(n=4)$. Quantitative data are represented as the number of positive pixels divided by the total pixels of the section. Statistical analysis was performed using a mixed effects model of repeated measures analysis of variance (ANOVA) and Tukey's post-hoc multiple comparisons test. Statistical differences between the mean \pm SEM of EAE and EAE-ASC are marked with ${ }^{* *} p<0.01 ;{ }^{* *} p<0.001$; and ${ }^{* * * *} p<0.0001$.

\subsection{ASC, but Not Rapa-ASC, Treatment Resulted in Elevated T Cell Marker in the CNS of EAE Mice}

The ability of ASC and Rapa-ASC therapy to modify both peripheral and CNS-permeated $\mathrm{T}$ cell populations was examined in EAE mice at DPI 30. As demonstrated by flow cytometric 
analysis of splenocytes, EAE-ASC mice exhibited a trend of increased $C D 4^{+}$Th cells and a decrease in $\mathrm{CD}^{+} / \mathrm{FOXP3}^{+} \mathrm{T}_{\text {reg }}$ cells (Figure $3 \mathrm{~A}$ ). Neither ASCs nor Rapa-ASCs significantly altered CD4 ${ }^{+} / \mathrm{CD} 8^{+} \mathrm{T}$ effector $\left(\mathrm{T}_{\text {eff }}\right)$ populations in the spleen (Figure $\left.3 \mathrm{~A}\right)$. Gene expression levels of $\mathrm{T}$ cell transcription factors (TFs) were robustly increased in the spinal cord after ASC, but not Rapa-ASC, treatment (Figure 3B). T-box expressed in T cells (Tbet) and GATA Binding Protein 3 (GATA3) are essential transcription factors for the differentiation of the pro-inflammatory $\mathrm{Th}_{1}$ and anti-inflammatory $\mathrm{Th}_{2} \mathrm{~T}$ helper cells, respectively [45]. Thet and GATA3 gene expression were upregulated in spinal cord tissue from EAE-ASC mice compared to EAE vehicle-treated controls. Forkhead Box P3 (FOXP3) is a key TF that drives the differentiation of $\mathrm{T}_{\text {regs }}$, which play crucial roles in quieting inflammation and promoting tissue regeneration [46]. Following ASC treatment, FOXP3 was increased more than 3-fold in the spinal cord compared to vehicle-treated EAE mice. While Rapa-preconditioned ASCs show trends toward enhanced Tbet and FOXP3 expression, this fails to reach statistical significance.

\section{Spleen}

A

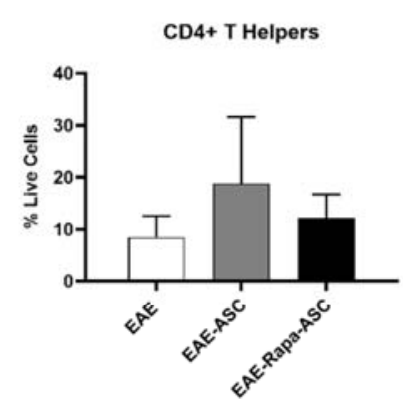

B

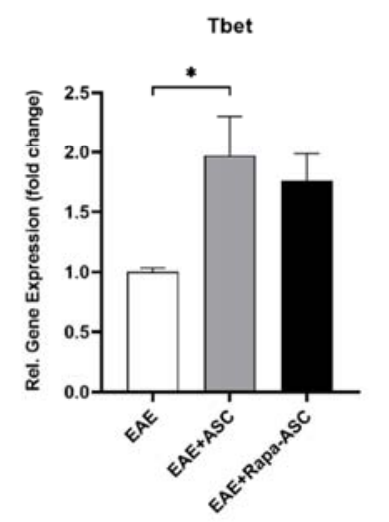

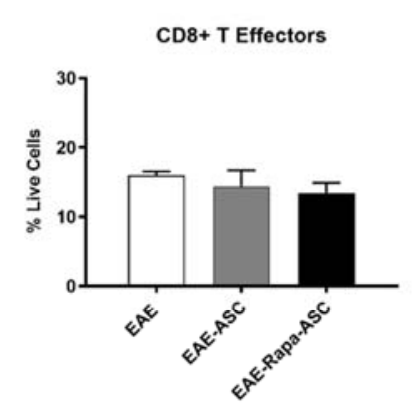

Spinal Cord

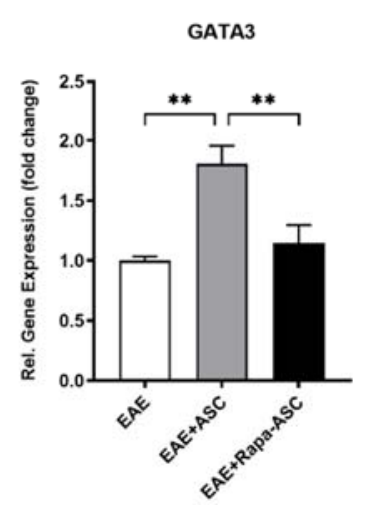

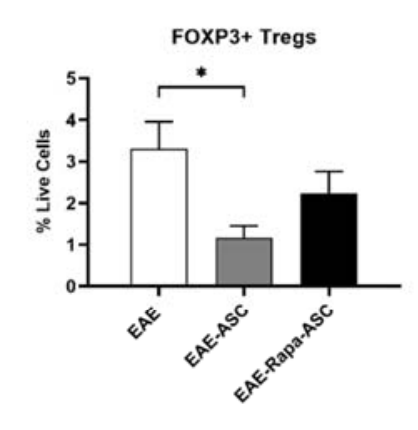

\section{(1)}

(1) 


\subsection{IL-10 Gene Expression is Significantly Increased with ASC-and Rapa-ASC-Treated EAE Mice}

We next examined gene expression of common $\mathrm{T}$ cell-derived cytokines that contribute to the anti-inflammatory and pro-regenerative activity of both $\mathrm{T}_{\text {regs }}$ and $\mathrm{Th}_{2}$ cells (Figure 4 ). $\mathrm{T}_{\text {regs }}$ produce high levels of transforming growth factor-beta (TGF- $\beta$ ) and interleukin-10 (IL-10), which both suppress differentiation of $\mathrm{Th}_{1}$ cells from naïve $\mathrm{CD} 4^{+} \mathrm{T}$ cells and suppress antigen presenting cell function [47]. At the transcriptional level, IL-10 showed a significant increase in EAE-ASC and to a lesser extent in EAE-Rapa-ASC mice as compared to EAE controls. No change, however, has been detected in TGF- $\beta$ or IL-4 gene expression. Activated $\mathrm{Th}_{2}$ cells produce high levels of IL-4, which can polarize macrophages and microglia towards the anti-inflammatory, M2 phenotype. After the administration of Rapa-ASCs to established EAE, a trend towards reduced IL-4 gene expression was observed in the spinal cord when compared with the control ASC treatment. Altogether, these findings indicate that ASC treatment is more effective than Rapa-ASCs at upregulating immune mediators in EAE.

A

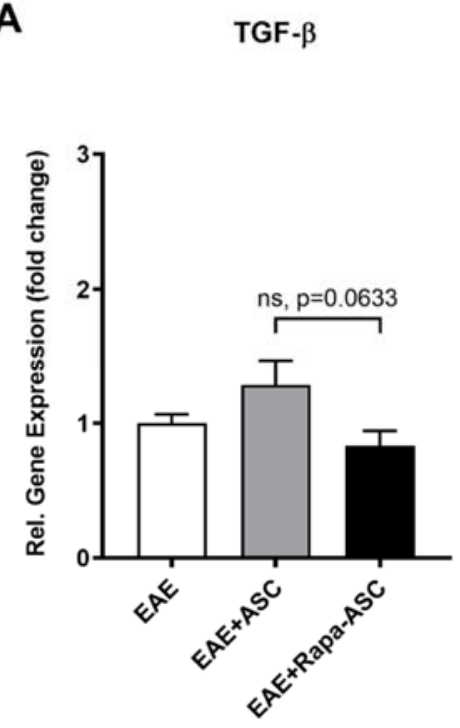

B

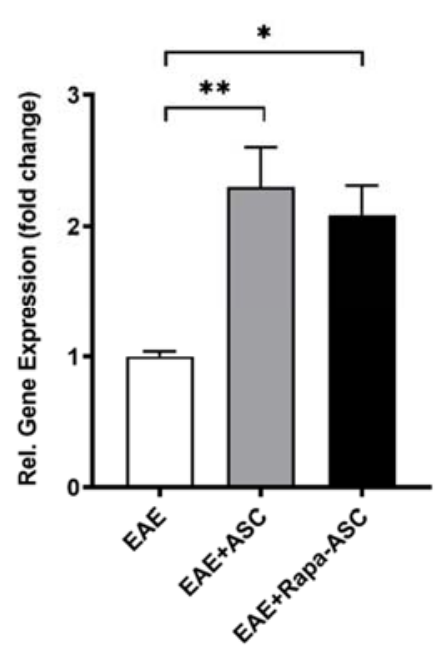

C

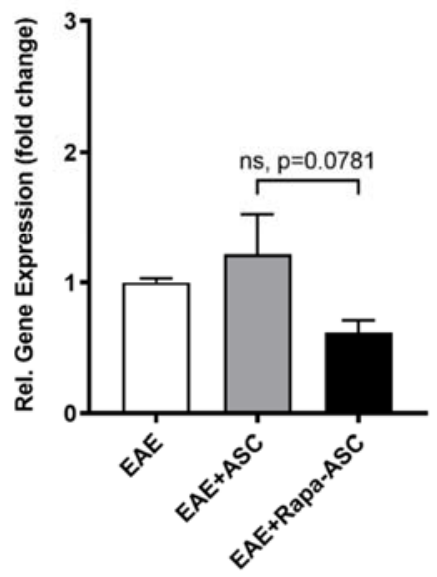

Figure 4. Gene expression analysis of T helper cell cytokines in the EAE spinal cord is altered by ASC treatments. Whole EAE spinal cords were analyzed using RT-qPCR for the T helper cell-derived cytokines TGF- $\beta$ (A), IL-10 (B), and IL-4 (C). Data are presented as the mean \pm SEM. Data are normalized to the housekeeping gene $\beta$-actin and represented as the relative fold change \pm SEM over vehicle-treated EAE controls. Statistical analysis was performed using a one-way analysis of variance (ANOVA) and Tukey's post-hoc multiple comparisons test. Statistical differences between groups are marked with ${ }^{*} p<0.05 ;{ }^{* *} p<0.01$. TGF- $\beta$, transforming growth factor-beta; IL-10, interleukin-10; IL-4, interleukin-4.

\section{Discussion}

Human ASCs have demonstrated robust therapeutic efficacy in preclinical models of MS [10,15,18-20,43,44], primarily through their immunoregulation of innate and adaptive immune cells $[48,49]$. However, clinical success with ASCs faces many challenges, including post-transplant apoptosis and weakened immunomodulatory potency [50]. Previous work suggests that short-term, but not long-term, inhibition of the mammalian target of rapamycin (mTOR) activity intensifies mesenchymal stem cell immunomodulation. In BMSCs, short-term Rapa results in elevated production of immune-modifying factors increased immunosuppression of PBMC or splenocyte proliferation, and protection against apoptosis following exposure to ischemia or oxygen-glucose deprivation [28,51]. In the present study, we examined the effect of short-term mTOR inhibition with Rapamycin on the immunomodulatory capacity of ASCs in the EAE mouse model of MS. Our results demonstrate that control ASCs exhibited significant therapeutic benefits when administered at DPI 20, as indicated by improved clinical scores, modestly better rotarod performance, and increased myelin levels in the 
lumbar spinal cord compared to vehicle-treated EAE mice. Surprisingly, EAE-Rapa-ASC mice failed to show measurable improvements in clinical scores, rotarod ability, or myelin levels, suggesting that Rapa preconditioning diminished the ASC immunoregulatory ability in vivo.

Prostaglandin E2, a pleiotropic molecule synthesized from arachidonic acid by COX2, has been implicated in the immunoregulatory actions of mesenchymal stem cell therapies in the EAE mouse. Anderson and colleagues have shown that mouse ASCs were able to suppress the pathophysiology and progression of EAE through robust inhibition of dendritic cell maturation and subsequent $\mathrm{T}$ cell proliferation [15]. Inhibition of COX2 abolished this effect on dendritic cells in vitro, indicating that PGE2 may be primarily responsible for the in vivo results [15]. Another study by Matysiak and collaborators demonstrated a therapeutic role for PGE2, but not IL-10 or TGF- $\beta$, in the EAE model. They administered a COX2 inhibitor in parallel with BMSC treatment, which resulted in reduced therapeutic efficacy [34]. While both groups have investigated PGE2 deprivation on stem cell therapies in the EAE model, none have examined whether elevated PGE2 enhances therapeutic benefits.

In vitro evidence from BMSCs showed short-term Rapa-mediated elevation of PGE2 signaling resulted in enhanced suppression of PBMC and splenocyte proliferation, suggesting that overexpressed PGE2 may amplify the benefit seen in EAE mice [30]. Therefore, the present study applied short-term Rapa preconditioning to ASCs and examined changes to therapeutic efficacy in EAE. The results indicate that control ASCs robustly reduced symptom severity and modestly improved performance on a fixed speed rotarod test. However, Rapa-ASCs demonstrated no similar improvements as compared to vehicle-treated EAE mice, indicating a loss of therapeutic potency. Timing of ASC administration may explain these findings, as others have shown that PGE2 plays temporally distinct roles in EAE pathogenesis and progression. A report by Esaki et al. illustrated a critical window of therapeutic benefit for PGE2 actions which may be mediated by its ability to prevent BBB permeabilization [37]. Their findings may highlight an unexpected benefit to the current investigation. Our laboratory previously demonstrated that human ASC therapy is highly effective prophylactically and therapeutically when administered at peak disease severity, but is less efficacious at suppressing disease progression if applied at DPI 8 , a time point correlative to T cell extravasation into CNS and emergence of initial motor symptoms [52-55]. Thus, if short-term Rapa elevate ASC-derived PGE2 and PGE2 prevents BBB breakdown, future investigations may determine whether Rapa-ASC treatment at this early pathogenic stage may inhibit extravasation of $\mathrm{T}$ cells.

$\mathrm{T}_{\text {regs }}$ play a crucial role in suppressing demyelination in EAE and are a critical factor of any therapeutic strategy. Selective depletion of $\mathrm{T}_{\text {regs }}$ from the $\mathrm{CNS}$ results in rampant $\mathrm{T}$ effector proliferation, pro-inflammatory cytokine production, and increased disease severity. $\mathrm{T}_{\text {regs }}$ have also exhibited robust suppression of antigen presenting cells, limiting their ability to activate T effector cells [56]. These indicate a significant role for $\mathrm{T}_{\text {regs }}$ in modulation of $\mathrm{T}$ effector functions [57]. Furthermore, ASC treatment of EAE mice at DPI 15 has demonstrated that enhancement of $\mathrm{T}_{\text {reg }}$ markers accompanies improved disease scores and reduced demyelination in the spinal cord $[18,44]$. The current study revealed changes to $\mathrm{T}_{\text {reg }}$ populations both in the periphery and in the spinal cord of EAE mice that received ASC treatment, but not those that received Rapa-ASC treatment, at DPI 20. As revealed by flow cytometric analysis of splenocytes, $\mathrm{CD} 4^{+} / \mathrm{FOXP}^{+} \mathrm{T}_{\text {regs }}$ are considerably reduced after ASC treatment, but not after Rapa-ASC or vehicle treatment. This correlates with a large transcriptional upregulation of the essential $\mathrm{T}_{\text {reg }}$ transcription factor, FOXP3, in the EAE spinal cord suggesting that peripheral $\mathrm{T}_{\text {regs }}$ may be mobilized by ASC but not Rapa-ASC or vehicle treatment. $\mathrm{T}_{\text {reg }}$ production of the cytokines TGF- $\beta$ and IL-10 are essential for their suppression of pathogenic autoreactive T cells [58]. In the spinal cord, both ASC and Rapa-ASC treatment resulted in elevated gene expression levels of IL-10, with ASCs resulting in the greatest elevation compared to vehicle-treated controls. However, neither treatment significantly altered TGF- $\beta$ transcripts in the spinal cord compared to vehicle controls. The data indicate that while ASC treatment at DPI 20 may enhance spinal cord markers of $\mathrm{T}_{\text {regs }}$, Rapa-ASCs exhibit a reduced capacity to promote $\mathrm{T}_{\text {reg }}$ functions in the CNS which correlates with a loss of symptomatic and rotarod improvement. 
Following activation by antigen-presenting cells, $\mathrm{CD} 4^{+} \mathrm{T}$ cells also differentiate into a variety of $\mathrm{T}$ helper phenotypes depending upon the cytokine milieu [59]. $\mathrm{Th}_{1}$ cells are classically pro-inflammatory and require the transcription factor Tbet for differentiation. In MS, $\mathrm{Th}_{1}$ cells are highly enriched in blood and CSF and secrete encephalitogenic cytokines that drive disease progression [60]. $\mathrm{Th}_{2}$ cells are considered anti-inflammatory and differentiate due to the activity of the transcription factor GATA3. In EAE, $\mathrm{Th}_{2}$ cells have displayed both pathogenic and immunoregulatory activities. $\mathrm{Th}_{2}$ cytokines can redirect autoreactive $\mathrm{Th}_{17}$ cell trafficking away from the CNS [61] and indirectly suppress $\mathrm{Th}_{1}$ cell function by regulating antigen-presenting cell activity [62]. However, they can also induce or exacerbate EAE in adoptive transfer models [63]. In EAE, both early and late therapeutic application of ASCs demonstrated immunomodulation of $\mathrm{T}$ cell cytokines, showing preferential promotion of IL-4 and IL-10 with concomitant suppression of IFN- $\gamma$ [18]. The current study interrogated $\mathrm{Th}_{1}$ and $\mathrm{Th}_{2}$ cell subsets to determine the immunomodulatory action of ASCs and Rapa-ASCs in the spleen and spinal cord. Flow cytometric analysis of splenocytes revealed a trend towards increased CD4 ${ }^{+} \mathrm{Th}$ cells in the ASCs, but not the Rapa-ASCs, treated spleen, suggesting that control ASCs have stronger immunoregulatory potential than Rapa-ASCs. A parallel effect was observed in the spinal cord, with both Tbet and GATA3 gene expression showing more significant upregulation in EAE-ASC than EAE-Rapa-ASC mice. However, the levels of IL-4 mRNA, an anti-inflammatory cytokine that both induces and is produced by $\mathrm{Th}_{2}$ cells, were not significantly different between groups.

Our data show that Rapa-ASCs resulted in significantly lower levels of $\mathrm{Th}_{2}$ cell differentiation markers, and a trend in lower $\mathrm{Th}_{1}$ and $\mathrm{T}_{\text {reg }}$ markers compared to control ASCs. Furthermore, examination of the $T_{\text {reg }}$ and $\mathrm{Th}_{2}$ cell-associated cytokines TGF- $\beta 1$, IL-10, and IL-4 revealed a trend toward lowered cytokine expression in the spinal cord of EAE-Rapa-ASC mice compared to control ASCs. Taken together, these findings suggest that the ability of Rapa-ASCs to modulate T cell differentiation and cytokine production after transplant into the EAE pathological environment is dampened compared to control ASCs. This may at least partially explain why intact myelin is lower in this group than both ASC and vehicle-treated controls. The balance of T cells is critically important for MS and EAE intervention, as was revealed by an investigation of global $\mathrm{CD} 4^{+} \mathrm{T}$ cell depletion in MS patients which resulted in no clinical benefit [64]. Based on our transcriptional data, we propose that control ASCs, but not Rapa-ASCs, may shift the balance in favor of $\mathrm{T}_{\text {reg }}$ and $\mathrm{Th}_{2}$ cells over $\mathrm{Th}_{1}$ cells and promote a CNS environment more favorable to oligodendrocyte protection, repair, or regeneration.

$\mathrm{Th}_{1}$-derived cytokines including IL-2, IL-12, and IFN $\gamma$ promote further proliferation of $\mathrm{Th}_{1}$ cells and inhibit proliferation of $\mathrm{Th}_{2}$ cells $[65,66]$. $\mathrm{Th}_{2}$-derived cytokines including IL-4 and IL-10, promote expansion of $\mathrm{Th}_{2}$ cells and inhibit the proliferation and function of $\mathrm{Th}_{1}$ cells $[65,66]$. $\mathrm{T}_{\text {regs }}$ suppress $\mathrm{T}$ effector and M1 macrophage activity, and their depletion in EAE mice resulted in elevated $\mathrm{T}_{\text {eff }}$ and macrophage proliferation and exacerbated disease severity [57].

While the focus of the current work was on $\mathrm{T}$ cell populations and associated cytokines, these play a crucial regulatory role in the activation of antigen-presenting cells such as infiltrating macrophages and resident microglia. $\mathrm{Th}_{1}$-derived cytokines activate M1-type microglia [67], while $\mathrm{Th}_{2}$-derived cytokines activate M2-type macrophages and microglia [68,69]. M1 activated macrophages and microglia have been found in early and active demyelinating lesions, suggesting their direct role in tissue destruction [70-72]. Furthermore, these cells produce pro-inflammatory cytokines and chemokines that activate astrocytes, impair the BBB, and recruit further encephalitogenic immune cells from the periphery [73]. Conversely, M2 macrophages and microglia have been implicated in remyelination in EAE [74]. Therefore, future investigations into macrophage and microglial phenotypes and associated neuroinflammatory cytokines may shed light on the worsened myelin loss in the EAE-Rapa-ASC spinal cord compared to both EAE and EAE-ASC animals.

Short-term Rapa exposure was hypothesized to enhance the therapeutic efficacy of ASCs. However, results from this study indicate that this preconditioning strategy eliminated their robust immunomodulatory effect. Rapa-ASCs were unable to preferentially promote $\mathrm{T}_{\text {reg }}$ and Th cell subsets, transcription of the anti-inflammatory cytokine IL-10, the increase in myelin levels, and improvement 
of rotarod performance when compared to ASC treatment. These findings emphasize that while novel preconditioning approaches may show promise in vitro or in direct co-culture studies, it is imperative to examine them in the context of physiologically relevant disease models. The disease course of MS and EAE is dynamic, with constantly shifting immune populations. Future studies should be conducted to determine whether this loss of therapeutic potential in Rapa-ASCs is limited to their application to advanced-stage disease, or whether there may be a critical window for which elevated PGE2 secretion is beneficial. The augmentation of ASC immunoregulatory capacity remains a significant obstacle for translational success. This study reveals that short-term Rapa may not be a viable approach for established EAE and should be interrogated for earlier disease applications. This work highlights the importance of investigating novel treatment strategies in animal models of disease, as in vitro work cannot effectively recapitulate the complexities of the in vivo pathological microenvironment.

Author Contributions: Conceptualization, R.M.W. and B.A.B.; methodology, R.M.W.; validation, R.M.W.; formal analysis, R.M.W.; investigation, R.M.W., M.A.A.H., B.N.S., I.A.P., S.J.A., A.T.V., E.R.M., and U.M.D.; data curation, R.M.W.; writing-original draft preparation, R.M.W.; writing-review and editing, R.M.W., M.A.A.H., B.N.S., and S.A.-G.; supervision, B.A.B.; resources, B.A.B.; project administration, B.A.B., funding acquisition, B.A.B. All authors have read and agreed to the published version of the manuscript.

Funding: The funds used for these studies were private funds from Tulane University.

Acknowledgments: The authors would like to thank Alan Tucker and the Flow Cytometry core and Dina Gaupp and the Histology core for their expertise.

Conflicts of Interest: The authors declare no conflict of interest.

\section{References}

1. Fletcher, J.M.; Lalor, S.J.; Sweeney, C.M.; Tubridy, N.; Mills, K.H.G. T cells in multiple sclerosis and experimental autoimmune encephalomyelitis. Clin. Exp. Immunol. 2010, 162, 1-11. [CrossRef] [PubMed]

2. Browne, P.; Chandraratna, D.; Angood, C.; Tremlett, H.; Baker, C.; Taylor, B.V.; Thompson, A.J. Atlas of multiple sclerosis 2013: A growing global problem with widespread inequity. Neurology 2014, 83, 1022-1024. [CrossRef] [PubMed]

3. Mckay, K.A.; Kwan, V.; Duggan, T.; Tremlett, H. Risk Factors Associated with the Onset of Relapsing-Remitting and Primary Progressive Multiple Sclerosis: A Systematic Review. BioMed Res. Int. 2015, 2015, 1-11. [CrossRef] [PubMed]

4. Tremlett, H.; Zhao, Y.; Devonshire, V. Natural history of secondary-progressive multiple sclerosis. Mult. Scler. 2008, 14, 314-324. [CrossRef] [PubMed]

5. Bross, M.; Hackett, M.; Bernitsas, E. Approved and Emerging Disease Modifying Therapies on Neurodegeneration in Multiple Sclerosis. Int. J. Mol. Sci. 2020, 21, 4312. [CrossRef]

6. Constantinescu, C.S.; Farooqi, N.; O’Brien, K.; Gran, B. Experimental autoimmune encephalomyelitis (EAE) as a model for multiple sclerosis (MS). Br. J. Pharmacol. 2011, 164, 1079-1106. [CrossRef]

7. Sabol, R.A.; Bowles, A.C.; Côté, A.; Wise, R.; Pashos, N.; Bunnell, B.A. Therapeutic Potential of Adipose Stem Cells; Springer: New York, NY, USA, 2018; pp. 1-11.

8. Zheng, G.; Qiu, G.; Ge, M.; He, J.; Huang, L.; Chen, P.; Wang, W.; Xu, Q.; Hu, Y.; Shu, Q.; et al. Human adipose-derived mesenchymal stem cells alleviate obliterative bronchiolitis in a murine model via IDO. Respir. Res. 2017, 18, 119. [CrossRef]

9. Gimble, J.M.; Katz, A.J.; Bunnell, B.A. Adipose-derived stem cells for regenerative medicine. Circ. Res. 2007, 100, 1249-1260. [CrossRef]

10. Semon, J.A.; Maness, C.; Zhang, X.; Sharkey, S.A.; Beuttler, M.M.; Shah, F.S.; Pandey, A.C.; Gimble, J.M.; Zhang, S.; Scruggs, B.A.; et al. Comparison of human adult stem cells from adipose tissue and bone marrow in the treatment of experimental autoimmune encephalomyelitis. Stem Cell Res. Ther. 2014, 5, 2. [CrossRef]

11. Bowles, A.C.; Strong, A.L.; Wise, R.M.; Thomas, R.C.; Gerstein, B.Y.; Dutreil, M.F.; Hunter, R.S.; Gimble, J.M.; Bunnell, B.A. Adipose Stromal Vascular Fraction-Mediated Improvements at Late-Stage Disease in a Murine Model of Multiple Sclerosis. Stem Cells 2017, 35, 532-544. [CrossRef] 
12. Bowles, A.C.; Wise, R.M.; Gerstein, B.Y.; Thomas, R.C.; Ogelman, R.; Febbo, I.; Bunnell, B.A. Immunomodulatory Effects of Adipose Stromal Vascular Fraction Cells Promote Alternative Activation Macrophages to Repair Tissue Damage. Stem Cells 2017, 35, 2198-2207. [CrossRef] [PubMed]

13. Zhang, X.; Bowles, A.C.; Semon, J.A.; Scruggs, B.A.; Zhang, S.; Strong, A.L.; Gimble, J.M.; Bunnell, B.A. Transplantation of Autologous Adipose Stem Cells Lacks Therapeutic Efficacy in the Experimental Autoimmune Encephalomyelitis Model. PLoS ONE 2014, 9, e85007. [CrossRef] [PubMed]

14. Melief, S.M.; Zwaginga, J.J.; Fibbe, W.E.; Roelofs, H. Adipose Tissue-Derived Multipotent Stromal Cells Have a Higher Immunomodulatory Capacity Than Their Bone Marrow-Derived Counterparts. Stem Cells Transl. Med. 2013, 2, 455-463. [CrossRef]

15. Anderson, P.; Gonzalez-Rey, E.; O'valle, F.; Martin, F.; Oliver, F.J.; Delgado, M. Allogeneic Adipose-Derived Mesenchymal Stromal Cells Ameliorate Experimental Autoimmune Encephalomyelitis by Regulating Self-Reactive T Cell Responses and Dendritic Cell Function. Stem Cells Int. 2017, 2017, 1-15. [CrossRef] [PubMed]

16. Payne, N.L.; Sun, G.; Mcdonald, C.; Layton, D.; Moussa, L.; Emerson-Webber, A.; Veron, N.; Siatskas, C.; Herszfeld, D.; Price, J.; et al. Distinct immunomodulatory and migratory mechanisms underpin the therapeutic potential of human mesenchymal stem cells in autoimmune demyelination. Cell Transplant. 2013, 22, 1409-1425. [CrossRef]

17. Constantin, G.; Marconi, S.; Rossi, B.; Angiari, S.; Calderan, L.; Anghileri, E.; Gini, B.; Bach, S.D.; Martinello, M.; Bifari, F.; et al. Adipose-derived mesenchymal stem cells ameliorate chronic experimental autoimmune encephalomyelitis. Stem Cells 2009, 27, 2624-2635. [CrossRef]

18. Shalaby, S.M.; Sabbah, N.A.; Saber, T.; Abdel Hamid, R.A. Adipose-derived mesenchymal stem cells modulate the immune response in chronic experimental autoimmune encephalomyelitis model. IUBMB Life 2016, 68, 106-115. [CrossRef]

19. Strong, A.L.; Bowles, A.C.; Wise, R.M.; Morand, J.P.; Dutreil, M.F.; Gimble, J.M.; Bunnell, B.A. Human Adipose Stromal/Stem Cells from Obese Donors Show Reduced Efficacy in Halting Disease Progression in the Experimental Autoimmune Encephalomyelitis Model of Multiple Sclerosis. Stem Cells 2016, 34, $614-626$. [CrossRef]

20. Scruggs, B.A.; Semon, J.A.; Zhang, X.; Zhang, S.; Bowles, A.C.; Pandey, A.C.; Imhof, K.M.P.; Kalueff, A.V.; Gimble, J.M.; Bunnell, B.A. Age of the Donor Reduces the Ability of Human Adipose-Derived Stem Cells to Alleviate Symptoms in the Experimental Autoimmune Encephalomyelitis Mo. Stem Cells Transl. Med. 2013, 2, 797-807. [CrossRef]

21. Seo, Y.; Shin, T.H.; Kim, H.S. Current strategies to enhance adipose stem cell function: An update. Int. J. Mol. Sci. 2019, 20, 3827. [CrossRef]

22. Li, J.; Kim, S.G.; Blenis, J. Rapamycin: One drug, many effects. Cell Metab. 2014, 19, 373-379. [CrossRef] [PubMed]

23. Kim, K.-W.; Moon, S.-J.; Park, M.-J.; Kim, B.-M.; Kim, E.-K.; Lee, S.-H.; Lee, E.-J.; Chung, B.-H.; Yang, C.-W.; Cho, M.-L. Optimization of adipose tissue-derived mesenchymal stem cells by rapamycin in a murine model of acute graft-versus-host disease. Stem Cell Res. Ther. 2015, 6, 202. [CrossRef] [PubMed]

24. Zhou, T.; Huang, Z.; Sun, X.; Zhu, X.; Zhou, L.; Li, M.; Cheng, B.; Liu, X.; He, C. Microglia Polarization with M1/M2 Phenotype Changes in rd1 Mouse Model of Retinal Degeneration. Front. Neuroanat. 2017, $11,77$. [CrossRef] [PubMed]

25. Lei, L.-T.; Chen, J.-B.; Zhao, Y.-L.; Yang, S.-P.; He, L. Resveratrol attenuates senescence of adipose-derived mesenchymal stem cells and restores their paracrine effects on promoting insulin secretion of INS-1 cells through Pim-1. Eur. Rev. Med. Pharmacol. Sci. 2016, 20, 1203-1213.

26. Gharibi, B.; Farzadi, S.; Ghuman, M.; Hughes, F.J. Inhibition of Akt/mTOR Attenuates Age-Related Changes in Mesenchymal Stem Cells. Stem Cells 2014, 32, 2256-2266. [CrossRef]

27. Antonioli, E.; Torres, N.; Ferretti, M.; de Azevedo Piccinato, C.; Sertie, A.L. Individual response to mTOR inhibition in delaying replicative senescence of mesenchymal stromal cells. PLoS ONE 2019, 14, e0204784. [CrossRef]

28. Li, C.; Ye, L.; Yang, L.; Yu, X.; He, Y.; Chen, Z.; Li, L.; Zhang, D. Rapamycin Promotes the Survival and Adipogenesis of Ischemia-Challenged Adipose Derived Stem Cells by Improving Autophagy. Cell. Physiol. Biochem. 2018, 44, 1762-1774. [CrossRef] 
29. Javorkova, E.; Vackova, J.; Hajkova, M.; Hermankova, B.; Zajicova, A.; Holan, V.; Krulova, M. The effect of clinically relevant doses of immunosuppressive drugs on human mesenchymal stem cells. Biomed. Pharmacother. 2018, 97, 402-411. [CrossRef]

30. Wang, B.; Lin, Y.; Hu, Y.; Shan, W.; Liu, S.; Xu, Y.; Zhang, H.; Cai, S.; Yu, X.; Cai, Z.; et al. mTOR inhibition improves the immunomodulatory properties of human bone marrow mesenchymal stem cells by inducing COX-2 and PGE2. Stem Cell Res. Ther. 2017, 8, 1-13. [CrossRef]

31. Gao, L.; Cen, S.; Wang, P.; Xie, Z.; Liu, Z.; Deng, W.; Su, H.; Wu, X.; Wang, S.; Li, J.; et al. Autophagy Improves the Immunosuppression of CD4+ T Cells by Mesenchymal Stem Cells Through Transforming Growth Factor- $\beta 1$. Stem Cells Transl. Med. 2016, 5, 1496-1505. [CrossRef]

32. Brock, T.G.; Mcnish, R.W.; Peters-Golden, M. Arachidonic Acid Is Preferentially Metabolized by Cyclooxygenase-2 to Prostacyclin and Prostaglandin E2. J. Biol. Chem. 1999, 274, 11660-11666. [CrossRef] [PubMed]

33. Gazdic, M.; Volarevic, V.; Arsenijevic, N.; Stojkovic, M. Mesenchymal Stem Cells: A Friend or Foe in Immune-Mediated Diseases. Stem Cell Rev. Rep. 2015, 11, 280-287. [CrossRef] [PubMed]

34. Matysiak, M.; Orlowski, W.; Fortak-Michalska, M.; Jurewicz, A.; Selmaj, K. Immunoregulatory function of bone marrow mesenchymal stem cells in EAE depends on their differentiation state and secretion of PGE2. J. Neuroimmunol. 2011, 233, 106-111. [CrossRef] [PubMed]

35. Schiffmann, S.; Weigert, A.; Männich, J.; Eberle, M.; Birod, K.; Häussler, A.; Ferreiros, N.; Schreiber, Y.; Kunkel, H.; Grez, M.; et al. PGE2/EP4 signaling in peripheral immune cells promotes development of experimental autoimmune encephalomyelitis. Biochem. Pharmacol. 2014, 87, 625-635. [CrossRef] [PubMed]

36. Kihara, Y.; Matsushita, T.; Kita, Y.; Uematsu, S.; Akira, S.; Kira, J.I.; Ishii, S.; Shimizu, T. Targeted lipidomics reveals mPGES-1-PGE2 as a therapeutic target for multiple sclerosis. Proc. Natl. Acad. Sci. USA 2009, 106, 21807-21812. [CrossRef]

37. Esaki, Y.; Li, Y.; Sakata, D.; Yao, C.; Segi-Nishida, E.; Matsuoka, T.; Fukuda, K.; Narumiya, S. Dual roles of PGE2-EP4 signaling in mouse experimental autoimmune encephalomyelitis. Proc. Natl. Acad. Sci. USA 2010, 107, 12233-12238. [CrossRef]

38. Dutra, R.C.; Moreira, E.L.G.; Alberti, T.B.; Marcon, R.; Prediger, R.D.; Calixto, J.B. Spatial reference memory deficits precede motor dysfunction in an experimental autoimmune encephalomyelitis model: The role of kallikrein-kinin system. Brain. Behav. Immun. 2013, 33, 90-101. [CrossRef]

39. Dutra, R.C.; Leite, D.F.P.; Bento, A.F.; Manjavachi, M.N.; Patrício, E.S.; Figueiredo, C.P.; Pesquero, J.B.; Calixto, J.B. The Role of Kinin Receptors in Preventing Neuroinflammation and Its Clinical Severity during Experimental Autoimmune Encephalomyelitis in Mice. PLoS ONE 2011, 6, e27875. [CrossRef]

40. Al-Ghadban, S.; Diaz, Z.T.; Singer, H.J.; Mert, K.B.; Bunnell, B.A. Increase in Leptin and PPAR- $\gamma$ Gene Expression in Lipedema Adipocytes Differentiated in vitro from Adipose-Derived Stem Cells. Cells 2020, 9 , 430. [CrossRef]

41. Sabol, R.A.; Villela, V.A.; Denys, A.; Freeman, B.T.; Hartono, A.B.; Wise, R.M.; Harrison, M.A.A.; Sandler, M.B.; Hossain, F.; Miele, L.; et al. Obesity-altered adipose stem cells promote radiation resistance of estrogen receptor positive breast cancer through paracrine signaling. Int. J. Mol. Sci. 2020, 21, 2722. [CrossRef]

42. Strong, A.L.; Hunter, R.S.; Jones, R.B.; Bowles, A.C.; Dutreil, M.F.; Gaupp, D.; Hayes, D.J.; Gimble, J.M.; Levi, B.; McNulty, M.A.; et al. Obesity inhibits the osteogenic differentiation of human adipose-derived stem cells. J. Transl. Med. 2016, 14, 27. [CrossRef] [PubMed]

43. Jafarinia, M.; Alsahebfosoul, F.; Salehi, H.; Eskandari, N.; Azimzadeh, M.; Mahmoodi, M.; Asgary, S.; Ganjalikhani Hakemi, M. Therapeutic effects of extracellular vesicles from human adipose-derived mesenchymal stem cells on chronic experimental autoimmune encephalomyelitis. J. Cell. Physiol. 2020, 235, 8779-8790. [CrossRef] [PubMed]

44. Li, J.; Chen, Y.; Chen, Z.; Huang, Y.; Yang, D.; Su, Z.; Weng, Y.; Li, X.; Zhang, X. Therapeutic effects of human adipose tissue-derived stem cell (hADSC) transplantation on experimental autoimmune encephalomyelitis (EAE) mice. Sci. Rep. 2017, 7, 1-10. [CrossRef] [PubMed]

45. Kanhere, A.; Hertweck, A.; Bhatia, U.; Gökmen, M.R.; Perucha, E.; Jackson, I.; Lord, G.M.; Jenner, R.G. T-bet and GATA3 orchestrate Th1 and Th2 differentiation through lineage-specific targeting of distal regulatory elements. Nat. Commun. 2012, 3, 1-12. [CrossRef] [PubMed]

46. Hori, S.; Nomura, T.; Sakaguchi, S. Control of regulatory T cell development by the transcription factor Foxp3. J. Immunol. 2017, 198, 981-985. [CrossRef] [PubMed] 
47. Batlle, E.; Massagué, J. Immunity Review Transforming Growth Factor-b Signaling in Immunity and Cancer. Immunity 2019, 50, 924-940. [CrossRef]

48. Serejo, T.R.T.; Silva-Carvalho, A.É.; Braga, L.D.d.C.F.; Neves, F.d.A.R.; Pereira, R.W.; Carvalho, J.L.d.; Saldanha-Araujo, F. Assessment of the Immunosuppressive Potential of INF- $\gamma$ Licensed Adipose Mesenchymal Stem Cells, Their Secretome and Extracellular Vesicles. Cells 2019, 8, 22. [CrossRef]

49. Fontanilla, C.V.; Gu, H.; Liu, Q.; Zhu, T.Z.; Zhou, C.; Johnstone, B.H.; March, K.L.; Pascuzzi, R.M.; Farlow, M.R.; Du, Y. Adipose-derived Stem Cell Conditioned Media Extends Survival time of a mouse model of Amyotrophic Lateral Sclerosis. Sci. Rep. 2015, 5, 16953. [CrossRef]

50. Patrikoski, M.; Mannerström, B.; Miettinen, S. Perspectives for Clinical Translation of Adipose Stromal/Stem Cells. Stem Cells Int. 2019, 2019, 1-21. [CrossRef]

51. Wang, G.; Yu, G.; Wang, D.; Guo, S.; Shan, F. Comparison of the purity and vitality of natural killer cells with different isolation kits. Exp. Ther. Med. 2017, 13, 1875-1883. [CrossRef]

52. Bowles, A.C.; Wise, R.M.; Gerstein, B.Y.; Thomas, R.C.; Ogelman, R.; Manayan, R.C.; Bunnell, B.A. Adipose stromal vascular fraction attenuates TH1 cell-mediated pathology in a model of multiple sclerosis. J. Neuroinflamm. 2018, 15, 77. [CrossRef]

53. Targoni, O.S.; Baus, J.; Hofstetter, H.H.; Hesse, M.D.; Karulin, A.Y.; Boehm, B.O.; Forsthuber, T.G.; Lehmann, P.V. Frequencies of Neuroantigen-Specific T Cells in the Central Nervous System Versus the Immune Periphery During the Course of Experimental Allergic Encephalomyelitis. J. Immunol. 2001, 166, 4757-4764. [CrossRef] [PubMed]

54. Kuerten, S.; Lehmann, P.V. The immune pathogenesis of experimental autoimmune encephalomyelitis: Lessons learned for multiple sclerosis? J. Interf. Cytokine Res. 2011, 31, 907-916. [CrossRef] [PubMed]

55. Guan, J.-L.; Simon, A.K.; Prescott, M.; Menendez, J.A.; Liu, F.; Wang, F.; Wang, C.; Wolvetang, E.; Vazquez-Martin, A.; Zhang, J. Autophagy in stem cells. Autophagy 2013, 9, 830-849. [CrossRef] [PubMed]

56. Onishi, Y.; Fehervari, Z.; Yamaguchi, T.; Sakaguchi, S. Foxp3+ natural regulatory T cells preferentially form aggregates on dendritic cells in vitro and actively inhibit their maturation. Proc. Natl. Acad. Sci. USA 2008, 105, 10113-10118. [CrossRef]

57. Koutrolos, M.; Berer, K.; Kawakami, N.; Wekerle, H.; Krishnamoorthy, G. Treg cells mediate recovery from EAE by controlling effector T cell proliferation and motility in the CNS. Acta Neuropathol. Commun. 2014, 2, 163. [CrossRef]

58. Zhang, X.; Koldzic, D.N.; Izikson, L.; Reddy, J.; Nazareno, R.F.; Sakaguchi, S.; Kuchroo, V.K.; Weiner, H.L. IL-10 is involved in the suppression of experimental autoimmune encephalomyelitis by CD25 + CD4 + regulatory T cells. Int. Immunol. 2004, 16, 249-256. [CrossRef]

59. Saravia, J.; Chapman, N.M.; Chi, H. Helper T cell differentiation. Cell. Mol. Immunol. 2019, 16, $634-643$. [CrossRef]

60. Restorick, S.M.; Durant, L.; Kalra, S.; Hassan-Smith, G.; Rathbone, E.; Douglas, M.R.; Curnow, S.J. CCR6+ Th cells in the cerebrospinal fluid of persons with multiple sclerosis are dominated by pathogenic non-classic Th1 cells and GM-CSF-only-secreting Th cells. Brain. Behav. Immun. 2017, 64, 71-79. [CrossRef]

61. Califano, D.; Sweeney, K.J.; Le, H.; VanValkenburgh, J.; Yager, E.; O'Connor, W.; Kennedy, J.S.; Jones, D.M.; Avram, D. Diverting T helper cell trafficking through increased plasticity attenuatesautoimmune encephalomyelitis. J. Clin. Investig. 2014, 124, 174-187. [CrossRef]

62. Ria, F.; Penna, G.; Adorini, L. Th1 cells induce and Th2 inhibit antigen-dependent IL-12 secretion by dendritic cells. Eur. J. Immunol. 1998, 28, 2003-2016. [CrossRef]

63. Lafaille, J.J.; Van De Keere, F.; Hsu, A.L.; Baron, J.L.; Haas, W.; Raine, C.S.; Tonegawa, S. Myelin basic protein-specific T helper 2 (Th2) cells cause experimental autoimmune encephalomyelitis in immunodeficient hosts rather than protect them from the disease. J. Exp. Med. 1997, 186, 307-312. [CrossRef] [PubMed]

64. Van Oosten, B.W.; Lai, M.; Hodgkinson, S.; Barkhof, F.; Miller, D.H.; Moseley, I.F.; Thompson, A.J.; Rudge, P.; McDougall, A.; McLeod, J.G.; et al. Treatment of multiple sclerosis with the monoclonal anti-CD4 antibody cM-T412: Results of a randomized, double-blind, placebo-controlled, MR- monitored phase II trial. Neurology 1997, 49, 351-357. [CrossRef] [PubMed]

65. O'Garra, A. Cytokines induce the development of functionally heterogeneous T helper cell subsets. Immunity 1998, 8, 275-283. [CrossRef]

66. Paludan, S.R. Interleukin- 4 and interferon- $\gamma$ : The quintessence of a mutual antagonistic relationship. Scand. J. Immunol. 1998, 48, 459-468. [CrossRef] 
67. Prajeeth, C.K.; Löhr, K.; Floess, S.; Zimmermann, J.; Ulrich, R.; Gudi, V.; Beineke, A.; Baumgärtner, W.; Müller, M.; Huehn, J.; et al. Effector molecules released by Th1 but not Th17 cells drive an M1 response in microglia. Brain. Behav. Immun. 2014, 37, 248-259. [CrossRef]

68. Katakura, T.; Miyazaki, M.; Kobayashi, M.; Herndon, D.N.; Suzuki, F. CCL17 and IL-10 as Effectors That Enable Alternatively Activated Macrophages to Inhibit the Generation of Classically Activated Macrophages. J. Immunol. 2004, 172, 1407-1413. [CrossRef]

69. Town, T.; Nikolic, V.; Tan, J. The microglial “activation" continuum: From innate to adaptive responses. J. Neuroinflamm. 2005, 2, 24. [CrossRef]

70. Bogie, J.F.J.; Stinissen, P.; Hendriks, J.J.A. Macrophage subsets and microglia in multiple sclerosis. Acta Neuropathol. 2014, 128, 191-213. [CrossRef]

71. Luo, C.; Jian, C.; Liao, Y.; Huang, Q.; Wu, Y.; Liu, X.; Zou, D.; Wu, Y. The role of microglia in multiple sclerosis. Neuropsychiatr. Dis. Treat. 2017, 13, 1661-1667. [CrossRef]

72. Vogel, D.Y.S.; Vereyken, E.J.F.; Glim, J.E.; Heijnen, P.D.A.M.; Moeton, M.; van der Valk, P.; Amor, S.; Teunissen, C.E.; van Horssen, J.; Dijkstra, C.D. Macrophages in inflammatory multiple sclerosis lesions have an intermediate activation status. J. Neuroinflamm. 2013, 10, 35. [CrossRef] [PubMed]

73. Wang, J.; Wang, J.; Wang, J.; Yang, B.; Weng, Q.; He, Q. Targeting Microglia and Macrophages: A Potential Treatment Strategy for Multiple Sclerosis. Front. Pharmacol. 2019, 10, 286. [CrossRef] [PubMed]

74. Miron, V.E.; Boyd, A.; Zhao, J.W.; Yuen, T.J.; Ruckh, J.M.; Shadrach, J.L.; Van Wijngaarden, P.; Wagers, A.J.; Williams, A.; Franklin, R.J.M.; et al. M2 microglia and macrophages drive oligodendrocyte differentiation during CNS remyelination. Nat. Neurosci. 2013, 16, 1211-1218. [CrossRef] [PubMed]

(C) 2020 by the authors. Licensee MDPI, Basel, Switzerland. This article is an open access article distributed under the terms and conditions of the Creative Commons Attribution (CC BY) license (http://creativecommons.org/licenses/by/4.0/). 